\title{
Interpreting paired serology for Ross River virus and Barmah Forest virus diseases
}

Jillann F Farmer, Andreas Suhrbier

\section{Background \\ Ross River virus (RRV) and Barmah Forest virus (BFV) cause approximately 4000 and 1000 cases, respectively, of rheumatic disease in Australia every year. Confirmation of a diagnosis usually involves testing for virus-specific immunoglobulin (Ig) M and IgG by a National Association of Testing Authorities-accredited pathology facility. \\ Objective \\ The aim of the article is to provide a logical framework by which clinicians can interpret paired RRV and BFV serology results in environments in which numerical antibody titres are no longer routinely provided. The traditional recommendation to look for an increase in titres is now largely obsolete.}

\section{Discussion}

Paired serology is clinical best practice but needs to be appropriately interpreted given the false positive and negative rates, the large number of asymptomatic infections and the long-term persistence of IgM in some individuals. An inappropriate interpretation risks a misdiagnosis.
ROSS RIVER VIRUS (RRV) and Barmah Forest virus (BFV) are two mosquitotransmitted arthritogenic alphaviruses that cause approximately 4000 and 1000 cases, respectively, of rheumatic disease in Australia annually. ${ }^{1}$ Most cases occur in northern Australia during the wet season (usually December to February) when mosquito numbers are high. ${ }^{2}$ The acute clinical symptoms of RRV disease are summarised in Table $1 ;^{1,3}$ arthropathy for RRV can be protracted, but generally lasts no longer than 3-6 months. ${ }^{1,4,5}$ Overall, BFV disease differs slightly, with patients tending to show less joint swelling, with the rash more common and more florid, and chronic disease substantially less prominent. ${ }^{6}$ As a result of overlapping symptoms, mosquito vectors and geographical locations, ${ }^{7,8}$ patients presenting with the aforementioned symptoms are usually tested for both viruses. Testing is done by enzyme-linked immunosorbent assay (ELISA)-based immunoglobulin (Ig) M and IgG serology, undertaken by a pathology laboratory using commercially available test kits.

In addition to symptomatic cases, $55-75 \%$ of RRV infections are asymptomatic. The number of asymptomatic BFV infections has not been formally evaluated, but is likely to be similar or higher than for RRV. ${ }^{9}$
Antibodies raised during an acute infection (irrespective of symptoms) are believed to confer protective immunity, ${ }^{1,10}$ which is most likely lifelong, given the absence in the literature of confirmed RRV re-infection cases. A correct interpretation of serology requires the clinician to distinguish between past and current infections. A past infection (perhaps decades earlier) does not explain a current acute illness. Incorrect interpretation of serology can lead to inappropriate attribution of an RRV/BFV diagnosis. Such a diagnostic error could delay correct identification of a more serious, but treatable, condition. Differential diagnosis includes other alphaviral arthritides (eg Sindbis, chikungunya), ${ }^{1}$ other viral arthritides (eg influenza, rubella, dengue) ${ }^{11}$ bacterial arthritides, ${ }^{12}$ autoimmune arthritides (eg rheumatoid arthritis, psoriatic arthritis), depression ${ }^{2,4}$ and medication reactions. Although traditionally a four-fold rise in paired serology titres was used as a diagnostic criterion (and remains part of many current guidelines),${ }^{13}$ such data are now no longer routinely provided. We have provided a logical framework by which clinicians can interpret paired RRV and $\mathrm{BFV}$ serology results in environments in which numerical antibody titre values are no longer routinely provided. 


\section{The principle of paired serology}

After an infectious mosquito bite, there is usually an incubation period of 7-9 days before disease develops in symptomatic cases, ${ }^{1}$ and in these cases the peak of alphaviral viraemia appears to coincide with disease onset. ${ }^{14}$ Alphaviral-specific IgM responses usually develop after day four post-onset of symptoms. ${ }^{15}$ Alphavirus-specific IgM usually lasts from 1-3 months, with levels generally falling after this time. ${ }^{1}$ Within two weeks of an elevated virus-specific IgM response, a virus-specific IgG level usually becomes detectable, with IgG levels persisting for a long period, probably for life. ${ }^{16}$ Changes in IgM and IgG levels over time (Figure 1A, blue arrows numbered 1-6) provide evidence that the disease in question is RRV/BFV (Table 2, scenarios 1-6). Taken together with appropriate accompanying clinical symptoms, such serology supports a diagnosis of RRV/BFV disease. RRV and BFV are notifiable diseases in Australia, with cases generally confirmed by serology.

\section{False positives and false negatives} Pathology facilities in Australia are accredited and inspected by the National Association of Testing Authorities (NATA), which require that facilities comply with a quality assurance program run by the Royal College of Pathologists of Australia. Sensitivity (true positive rate) and specificity (true negative rate) values for Panbio RRV IgG ELISA provided by the company are both $100 \%$. For the RRV kits, the sensitivity and specificity values for IgM are $96 \%$ and $99 \%$, respectively. ${ }^{17}$ For the BFV kits, the sensitivity and specificity values for IgG are $100 \%$ and $93 \%$, and values for IgM are $97 \%$ and $94 \%,{ }^{18}$ respectively. Individual pathology facilities often adopt and validate their own protocols and use their own reference reagents, which may improve these values; however, 100\% reliability for IgM testing is currently not achievable. The aforementioned percentages would, for instance, predict that $3 \%$ of $\mathrm{BFV}$ IgM results are false positives and 6\% are false negatives. An increase in false positive BFV IgM results also appears to have occurred in the Northern Territory in 2012-2013, likely due to faulty ELISA kits. ${ }^{19}$

A serosurvey of sera from ostensibly healthy blood donors by the Australian Red Cross Blood Service (using the Panbio kits) provided a positive rate of approximately $1.2 \%$ for BFV IgM and approximately $1.7 \%$ for IgG. ${ }^{9}$ For RRV these figures were $0.9 \%$ positive for IgM and approximately $8.4 \%$ positive for IgG. ${ }^{9}$ The IgG percentages are consistent with other studies. ${ }^{9}$ For the population of Queensland (4.6 million), a 0.9\% IgM rate would imply 41,400 recent RRV infections. With a $25 \%$ symptomatic rate, this implies approximately 10,000 blood donors who 1) were ostensibly healthy at the time of blood donation and 2) subsequently developed RRV disease that they did not report. ${ }^{9,20}$ As this is clearly improbable, the high percentage of IgM+ results likely includes false positives (refer to the section about persistent IgM later in this article).

Laboratories occasionally report an equivocal +/- result. These should also be interpreted using the described appropriate changes in paired serology (Figure 1; Table 2). For instance, sequential identical equivocal results are inconsistent with a diagnosis of acute RRV/BFV. Whether patients infected with serologically related arthritogenic alphaviruses (eg chikungunya virus, Mayaro virus, o'nyong nyong) ${ }^{1}$ would return a positive result in the RRV/BFV ELISA tests has not been definitively studied. A travel history would guide the clinician to the appropriate investigations.

RRV and BFV serology is therefore not $100 \%$ reliable and needs to be interpreted with caution. The statement 'suggests recent infection', provided with an IgM+ pathology test result, should similarly be treated with caution. Paired serology will improve the chances of a correct serodiagnosis (Table 2). Although viral nucleic acid detection assays are available, ${ }^{21}$ they need to be applied during the 5-7-day viraemic period (Figure 1) and are thus usually unhelpful in resolving ambiguous serology.

\section{Table 1. Acute Ross River virus disease symptoms*}

\begin{tabular}{llll}
\hline Symptom & Period & Percentage of patients & Notes \\
\hline Fever & Approximately 1 week & $20-60$ & Can be rapid onset \\
\hline Polyarthralgia/polyarthritis & Up to 3-6 months & $80-100$ & $\begin{array}{l}\text { Onset usually contemporaneous with } \\
\text { fever; mainly peripheral joints and usually } \\
\text { symmetrical distribution }\end{array}$ \\
\hline Rash & Approximately 5-10 days & $40-60$ & $\begin{array}{l}\text { Commonly maculopapular (1-5 mm in } \\
\text { diameter), may be vesicular or purpuric; } \\
\text { usually starts a few days post-onset of } \\
\text { symptoms }\end{array}$ \\
\hline Myalgia & Approximately 1 week & $40-80$ & Non-specific
\end{tabular}

${ }^{*}$ A diagram describing the joints affected by Ross River virus arthropathy is available from Prow et al (supplementary information). ${ }^{3}$ Fatigue (>50\%) is often also noted as a symptom and can be protracted, but has limited diagnostic value. Other symptoms can include headache, photophobia, lymphadenopathy, sore throat and, rarely, encephalitis. ${ }^{2,29}$ 


\section{Persistent Ig $\mathbf{M}$}

Although IgM levels usually drop below detection after 1-3 months, in some patients an $\operatorname{IgM}+/ \operatorname{IgG}+$ alphaviral serology result can persist for an extended period. ${ }^{22,23}$ In one study of paired serology, 19 of 116 (16.3\%) patients with RRV showed a persistent IgM response lasting between 7 months and 8 years (with patients not followed-up to check if their IgM levels dropped). ${ }^{24}$ The extended persistence of IgM+ results is not restricted to alphavirus serodiagnoses, but has also been reported for commercial dengue virus serology assays. ${ }^{25}$ Thus, paired serology tests, with both results returning an IgM+/IgG+ result (Table 2, scenario 8), do not provide strong evidence for a recent RRV/BFV infection.
Despite incidental findings, ${ }^{23}$ there is no compelling evidence that 1) persistent IgM has clinical relevance, ${ }^{22}$ 2) re-exposure can significantly increase IgM levels or 3) reinfection or reactivation occurs, given the likely lifelong immunity.

\section{Common pitfalls}

A number of common errors can result in a misdiagnosis or an inability to make a serologically confirmed diagnosis.

1. Relying on a single test risks inappropriate diagnosis. ${ }^{26}$ Even an IgM+/IgG- result would benefit from a second test $>2$ weeks later to confirm the diagnosis. Clinically appropriate symptomatic treatment (usually non-steroidal anti-inflammatory medications and/or paracetamol) should nevertheless be provided without waiting for confirmation.

2. Testing too soon, before IgM has reached detectable levels, may generate an IgM-/IgG- result. If not followed up with a second test $>2$ weeks later (Table 2, scenarios 1-3), the clinician may fail to diagnose RRV/BFV disease.

3. A test result of $\operatorname{IgM}+/ \operatorname{IgG}+$, or paired serology tests with both results returning IgM+/IgG+, does not provide strong evidence of a recent infection (Table 2, scenario 8). IgM levels usually drop after 1-3 months, but an IgM+ serology result can occur for an extended period after infection. This phenomenon likely also arises after asymptomatic infections. ${ }^{9}$ A third test after this period giving an

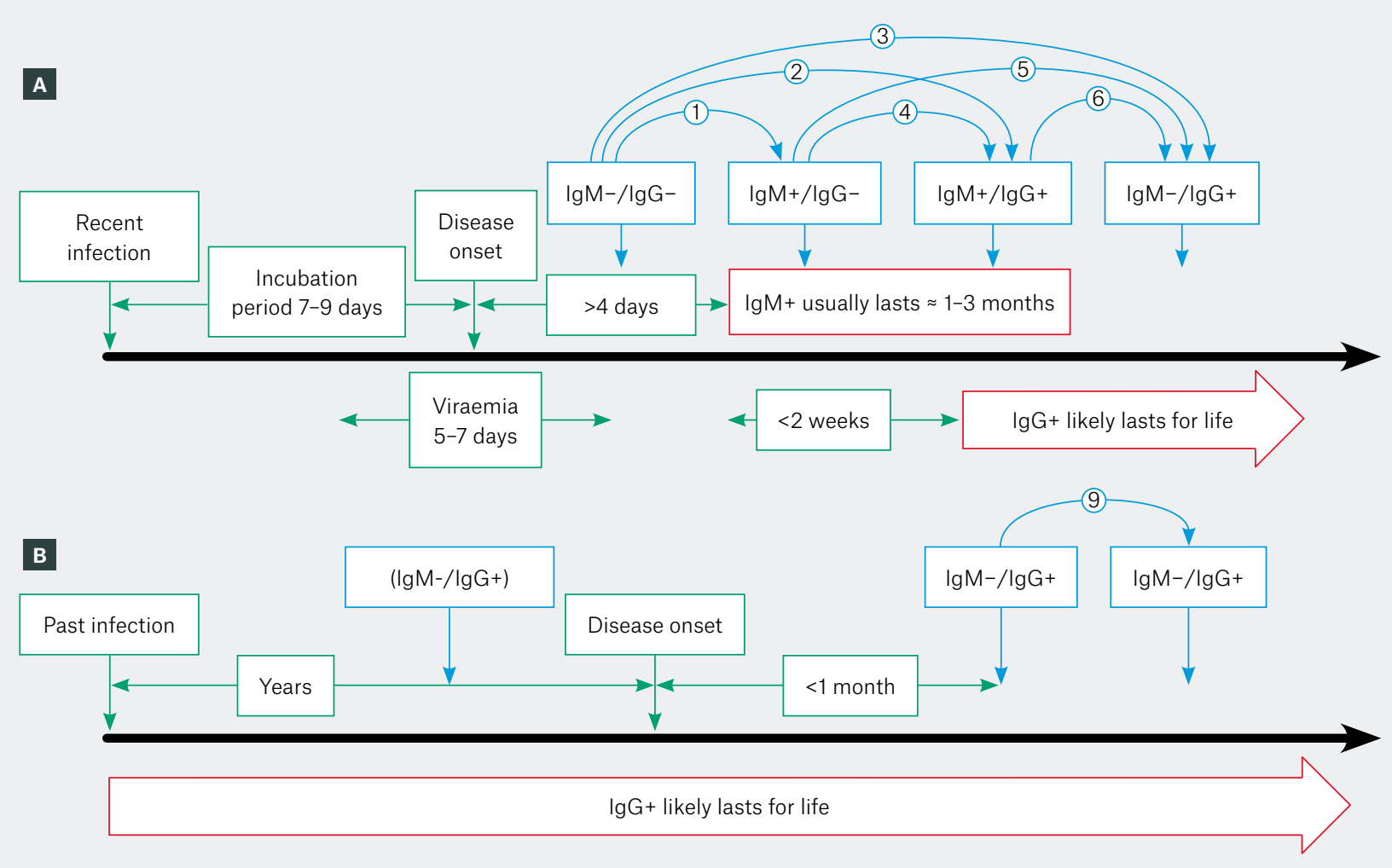

Figure 1. RRV/BFV infection and RRV/BFV serology results. Blue arrows with numbers correspond with Table 1 paired serology results. A. Serology consistent with a recent infection. The blue arrows numbered 1-6 indicate changes in $\operatorname{lgM} / \lg$ results over time that are consistent with a recent infection; B. Serology consistent with a past infection. After an RRV/BFV infection the patient becomes $\operatorname{lgM}-/ \lg \mathrm{G}+$, although this test may not have been undertaken (prior to disease onset) because the infection was asymptomatic or any disease associated with the past infection went undiagnosed. If serology is taken within a month of disease onset, paired $\lg M-/ \lg \mathrm{G}+$ results are not consistent with a recent RRV/BFV infection.

BFV, Barmah Forest virus; Ig, immunoglobulin; RRV, Ross River virus 
IgM-/IgG+ result provides evidence for RRV disease; however, at this stage disease may have largely resolved and serology can only provide confirmation of a prior clinical diagnosis.

4. A late test (1-3 months post-onset of disease) giving an IgM-/IgG+ result provides no evidence for a recent RRV infection, only evidence of a past infection (Figure 1B; Table 2, scenario 9). Subsequent paired serology can only rule out an (uncommon) false positive IgG+ result. Serology is therefore of limited value if initiated after the IgM levels have already dropped. Identification of a previous IgG-result on the patient's medical record may provide diagnostic assistance.

5. More than one month will likely have passed by the time two serology results >2 weeks apart have been obtained; after this time, follow-up serology for other diseases would be difficult for reasons outlined in the previous paragraph. Therefore, the BFV and RRV tests should be ordered together. A patient who has recently returned from certain overseas destinations might initially be tested for other alphaviruses such as chikungunya virus. ${ }^{1}$ Dengue virus infections can also lead to arthropathy ${ }^{11}$ and might be considered at the onset of symptoms if the patient had recently travelled to a dengue area or had travelled to, or resided in, northern Queensland, where outbreaks often occur during summer.

\section{Persistent rheumatic disease}

RRV disease usually lasts no more than 3-6 months; ${ }^{4,5}$ the period of BFV disease is usually considerably shorter. ${ }^{6} \mathrm{~A}$ post-infective fatigue syndrome has also been reported in a minority of patients with RRV disease. ${ }^{27}$ There is no evidence that alphaviral arthritides predispose to autoimmune disease; however, symptoms, inflammatory mechanisms, ${ }^{28}$ and demographics often overlap. ${ }^{4,6}$ An RRV/BFV diagnosis is therefore generally unlikely to explain rheumatic disease that has lasted for $>3-6$ months. Such a mistaken diagnosis risks failure to identify a potentially more

\begin{tabular}{|c|c|c|c|}
\hline Scenario & $\begin{array}{l}\text { First } \\
\lg M / \lg G\end{array}$ & $\begin{array}{l}\text { Second } \\
\lg M / \lg G\end{array}$ & Interpretation \\
\hline \multicolumn{4}{|c|}{ Paired serology consistent with recent infection } \\
\hline 1 & $-/-$ & $+/-$ & $\begin{array}{l}\text { The first serum collected early in infection } \\
\text { before IgM levels have reached detectable } \\
\text { levels; the second sample taken before lgG } \\
\text { levels have reached detectable levels }\end{array}$ \\
\hline 2 & $-/-$ & $+/+$ & $\begin{array}{l}\text { The second sample taken taken after both IgM } \\
\text { and IgG levels have reached detectable levels }\end{array}$ \\
\hline 3 & $-/-$ & $-/+$ & $\begin{array}{l}\text { Elevated IgM usually lasts approximately } \\
1-3 \text { months and may have risen and fallen in } \\
\text { the period between the two tests; if the period } \\
\text { is }<4-6 \text { weeks, retesting is recommended }\end{array}$ \\
\hline 4 & $+/-$ & $+/+$ & $\begin{array}{l}\text { The first serum collected after IgM levels have } \\
\text { reached detectable levels; the second sample } \\
\text { taken before IgM levels have fallen and after } \\
\text { IgG levels have reached detectable levels }\end{array}$ \\
\hline 5 & $+/-$ & $-/+$ & $\begin{array}{l}\text { The second sample taken after lgM levels } \\
\text { have fallen and after lgG levels have reached } \\
\text { detectable levels }\end{array}$ \\
\hline 6 & $+/+$ & $-/+$ & $\begin{array}{l}\text { The first serum collected after lgM and } \lg G \\
\text { levels have reached detectable levels }\end{array}$ \\
\hline
\end{tabular}

\section{Paired serology not consistent with recent infection}

\begin{tabular}{cccl}
\hline 7 & $-/-$ & $-/-$ & Reliable negative result if taken $>2$ weeks apart \\
\hline 8 & $+/+$ & $+/+$ & $\begin{array}{l}\text { Could retest if interval <3 months; IgM-/IgG+ } \\
\text { would be consistent with recent infection (refer } \\
\text { to scenario } 6), \lg M+/ \lg \text { + would be consistent } \\
\text { with past infection with persistent IgM }\end{array}$ \\
\hline 9 & $-/+$ & $-/+$ & Evidence of past infection
\end{tabular}

\begin{tabular}{|c|c|c|c|}
\hline \multicolumn{4}{|c|}{ Paired serology suggesting false positives or false negatives (consider retesting) } \\
\hline 10 & $+/-$ & $+/-$ & $\begin{array}{l}\text { If taken } \geq 2 \text { weeks apart suggests IgM false } \\
\text { positive (or lgG false negative), consider retest }\end{array}$ \\
\hline 11 & $+/+$ & $-/-$ & \multirow{4}{*}{$\begin{array}{l}\text { lgG usually lasts for life so lgG is unlikely to } \\
\text { become negative }\end{array}$} \\
\hline 12 & $+/+$ & $+/-$ & \\
\hline 13 & $-/+$ & $+/-$ & \\
\hline 14 & $-/+$ & $-/-$ & \\
\hline 15 & $-/+$ & $+/+$ & $\begin{array}{l}\text { Reinfection or reactivation not recognised } \\
\text { phenomena }\end{array}$ \\
\hline 16 & $+/-$ & $-/-$ & $\lg M$ positive is usually followed by $\lg G$ positive \\
\hline
\end{tabular}

Ig, immunoglobulin

serious and treatable condition such as an autoimmune disease or depression. ${ }^{4}$

In a patient with a chronic rheumatic disease that has lasted for $>3-6$ months, an RRV/BFV test is unlikely to be helpful. First, as discussed above, this is too late for serology to provide useful diagnostic insights (Table 2, scenario 9). Second, and perhaps more importantly, an IgG+ result may inappropriately reinforce for the patient the common misconception that $\mathrm{RRV} / \mathrm{BFV}$ disease lasts for a very long time 
and cannot be effectively treated, thereby ameliorating their desire to seek a correct diagnosis and appropriate treatment.

\section{Key points}

- Many guidelines advise that a positive RRV/BFV serodiagnosis can be made based on a $>4$-fold increase in titres in paired serology. Such titres are no longer routinely provided by pathology companies.

- A positive RRV/BFV diagnosis requires a change in paired serology results consistent with transient (1-3 months) IgM followed by long-term IgG (eg IgM-/IgG- to IgM+/IgG- or $\mathrm{IgM}+/ \mathrm{IgG}-$ to $\operatorname{IgM}+/ \mathrm{IgG}+$ ).

- Past and asymptomatic infections must be distinguished from recent infections in light of false positive and false negative serology results and the presence of persistent IgM in some individuals.

\section{Authors}

Jillann F Farmer MBBS (Hons), FRACGP, MHA, FRACMA, MACRRM, Medical Director of the United Nations' Medical Service Division, New York, NY, USA Andreas Suhrbier BA (Hons), MA, PhD, Group Leader, Inflammation Biology Laboratory, Division of Infectious Diseases and Immunology, QIMR Berghofer Medical Research Institute, Brisbane, Qld. Andreas.Suhrbier@qimrberghofer.edu.au

Competing interests: AS is a Principal Research Fellow of the National Health and Medical Research Council (NHMRC) and has conducted research projects with the Royal Australian College of General Practitioners (RACGP) on RRV. JF is a Fellow of the RACGP and is currently the Medical Director of the United Nations' Medical Services Division. The views and opinions expressed in this article are those of the authors and do not necessarily reflect the official policy or position of the United Nations.

Funding: None.

Provenance and peer review: Not commissioned, externally peer reviewed.

\section{References}

1. Suhrbier A, Jaffar-Bandjee MC, Gasque P. Arthritogenic alphaviruses - An overview. Nature Rev Rheumatol 2012;8(7):420-29. doi: 10.1038/ nrrheum.2012.64.

2. Harley D, Suhrbier A. Ross river virus disease. In: Ryan ET, Hill DR, Solomon T, Aronson N, Endy TP. Hunter's tropical medicine and emerging infectious diseases. 10th edn. Edinburgh: Elsevier, 2019. p. 342-43.

3. Prow NA, Tang B, Gardner J, et al. Lower temperatures reduce type I interferon activity and promote alphaviral arthritis. PLoS Pathog 2017;13(12):e1006788. doi: 10.1371/journal. ppat.1006788.

4. Mylonas AD, Brown AM, Carthew TL, et al. Natural history of Ross River virus-induced epidemic polyarthritis. Medical J Aust 2002;177(7):356-60. doi: 10.5694/j.1326-5377.2002.tb04837.x.
5. Harley D, Bossingham D, Purdie DM, Pandeya N, Sleigh AC. Ross River virus disease in tropical Queensland: Evolution of rheumatic manifestations in an inception cohort followed for six months. Medical J Aust 2002;177(7):352-55. doi: 10.5694/j.1326-5377.2002.tb04836.x.

6. Flexman JP, Smith DW, Mackenzie JS, et al. A comparison of the diseases caused by Ross River virus and Barmah Forest virus. Med J Aust 1998;169(3):159-63.

7. Jacups SP, Whelan PI, Currie BJ. Ross River virus and Barmah Forest virus infections: A review of history, ecology, and predictive models, with implications for tropical northern Australia. Vector Borne Zoonotic Dis 2008;8(2):283-97. doi: 10.1089/vbz.2007.0152.

8. Gyawali N, Bradbury RS, Aaskov JG Taylor-Robinson AW. Neglected Australian arboviruses: Quam gravis? Microbes Infect 2017;19(7-8):388-401. doi: 10.1016/j. micinf.2017.05.002

9. Faddy $H$, Dunford M, Seed C, et al. Seroprevalence of antibodies to Ross River and Barmah Forest viruses: Possible implications for blood transfusion safety after extreme weather events. Ecohealth 2015;12(2):347-53. doi: 10.1007/ s10393-014-1005-0.

10. Wressnigg $N$, van der Velden MVW, Portsmouth $D$, et al. An inactivated Ross River virus vaccine is well tolerated and immunogenic in an adult population in a randomized phase 3 trial. Clin Vaccine Immunol 2015;22(3):267-73. doi: 10.1128/CVI.00546-14.

11. Suhrbier $A$, Mahalingam $S$. The immunobiology of viral arthritides. Pharmacol Ther 2009;124(3):301-08. doi: 10.1016/j.pharmthera.2009.09.005.

12. Hassan AS, Rao A, Manadan AM, Block JA Peripheral bacterial septic arthritis: Review of diagnosis and management. J Clin Rheumatol 2017;23(8):435-42. doi: 10.1097/ RHU.0000000000000588.

13. Lab Tests Online Australasia. Ross River fever: Tests. Alexandria, NSW: Lab Tests Online Australasia, 2019. Available at www.labtestsonline. org.au/learning/index-of-conditions/ross-river/ tests [Accessed 24 May 2019].

14. Riswari SF, Ma'roef CN, Djauhari $\mathrm{H}$, et al. Study of viremic profile in febrile specimens of chikungunya in Bandung, Indonesia. J Clin Virol 2015;74:61-65. doi: 10.1016/j.jcv.2015.11.017.

15. Chua CL, Sam IC, Chiam CW, Chan YF. The neutralizing role of IgM during early Chikungunya virus infection. PLoS One 2017;12(2):e0171989. doi: 10.1371/journal.pone.0171989.

16. Kistner O, Barrett PN, Brühmann A, et al. The preclinical testing of a formaldehyde inactivated Ross River virus vaccine designed for use in humans. Vaccine 2007;25(25):4845-52. doi: 10.1016/j.vaccine.2007.01.103.

17. Abbott. Panbio Ross River Virus IgM ELISA. California, USA: Abbott, 2019. Available at www.alere.com/en/home/product-details/ panbio-ross-river-virus-igm-elisa-au.html [Accessed 23 May 2019].

18. Abbott. Panbio Barmah Forest Virus IgM ELISA. California, USA: Abbott, 2019. Available at www. alere.com/en/home/product-details/panbiobarmah-forest-virus-igm-elisa.html [Accessed 24 May 2019].

19. Kurucz N, Markey P, Draper A, et al. Investigation into high Barmah Forest virus disease case numbers reported in the Northern Territory, Australia in 2012-2013. Vector Borne Zoonotic Dis 2016;16(2):110-16. doi: 10.1089/vbz.2015.1801.

20. Hoad VC, Speers DJ, Keller AJ, et al. First reported case of transfusion-transmitted Ross River virus infection. Med J Aust 2015;202(5):267-69. doi: 10.5694/mja14.01522.
21. Sellner LN, Coelen RJ, Mackenzie JS. Detection of Ross River virus in clinical samples using a nested reverse transcription-polymerase chain reaction. Clin Diagn Virol 1995;4(3):257-67. doi: 10.1016/0928-0197(95)00009-W.

22. Niklasson B, Espmark $\ddot{A}$, Lundström J. Occurrence of arthralgia and specific IgM antibodies three to four years after Ockelbo disease. J Infect Dis 1988;157(4):832-35. doi: 10.1093/infdis/157.4.832.

23. Malvy D, Ezzedine K, Mamani-Matsuda M, et al. Destructive arthritis in a patient with chikungunya virus infection with persistent specific $\lg \mathrm{M}$ antibodies. BMC Infect Dis 2009;9(1):200. doi: 10.1186/1471-2334-9-200.

24. Kapeleris J, Lowe P, Phillips D, Wyatt D, Batham M, Devine P. IgG avidity in the diagnosis of acute Ross River virus infection. Dis Markers 1996;12(4):279-82. doi: 10.1155/1996/756940.

25. Chien YW, Liu ZH, Tseng FC, et al. Prolonged persistence of $\mathrm{lgM}$ against dengue virus detected by commonly used commercial assays. BMC Infect Dis 2018;18(1):156. doi: 10.1186/ s12879-018-3058-0.

26. Selvey LA, Donnelly JA, Lindsay MD, Pottumarthy Boddu S, D'Abrera VC, Smith DW. Ross River virus infection surveillance in the Greater Perth Metropolitan area - has there been an increase in cases in the winter months? Commun Dis Intell 2014;38(2):E114-E22.

27. Hickie I, Davenport T, Wakefield D, et al. Post-infective and chronic fatigue syndromes precipitated by viral and nonviral pathogens: Prospective cohort study. BMJ 2006;333(7568):575. doi: 10.1136/ bmj.38933.585764.AE.

28. Nakaya HI, Gardner J, Poo Y-S, Major L, Pulendran B, Suhrbier A. Gene profiling of Chikungunya virus arthritis in a mouse model reveals significant overlap with rheumatoid arthritis. Arthritis Rheum 2012;64(11):3553-63. doi: 10.1002/art.34631.

29. Harley D, Sleigh A, Ritchie S. Ross River virus transmission, infection, and disease: $A$ cross-disciplinary review. Clin Microbiol Rev 2001;14(4):909-32. doi: 10.1128/CMR.14.4.909932.2001. 